\title{
3 \\ Multiple perspectives on intellectual property
}

\section{Marilyn Strathern}

The concept of intellectual property has opened up possibilities for the legal protection of rights to intangible resources, including the products of knowledge and other forms of creativity. It has thus become one possible route to recognising the holders of the 'knowledge, innovations and practices of indigenous and local communities embodying traditional lifestyles relevant for the conservation of and sustainable use of biological diversity' (Convention on Biological Diversity, Article 8(j)). The Convention leaves it open as to how signatory nations are to respond but cautions them over intellectual property rights agreements lest these run counter to rather than support its objectives (Article 16.5).

Intellectual property has suddenly become a topic of widespread international interest. Moreover, once articulated, it rapidly catches the public imagination, and this is something to be taken into account in policy development. What makes it such a powerful and debatable topic? The first part of this chapter suggests it is important to understand the Euro-American culture which has produced the intellectual property concept as well the cultures which may adopt it. Assumptions and practices originating from northern Europe and North America inform many values that the international community takes for granted. Less obvious is the fact that these include some of the ways in which not just support of but opposition to intellectual property rights has been expressed. Further, Euro-American culture, like any other, is constantly changing, and stereotypes get out of step with current social realities. These offer points for debate in the second part of the chapter. 
One approach to weighing up the advantages and disadvantages of intellectual property rights is contained in the very notion of property. At the heart of Euro-American ideas lies a creative ambiguity: on the one hand property refers to things and on the other hand to social relations (Hann 1997). Things may or may not be tangible; property is equally the thing in which a person holds rights and those rights themselves. In the second sense, property points to a set of relations between persons with respect to a thing, for claims are always made by persons in relation to others and within a field of relationships which recognise those claims. Thus the Convention on Biological Diversity has created a new arena in which rights may be negotiated. These terms (things and relations) are useful more generally as points of entry into the debate. As the Papua New Guinean material shows, however, they are useful only up to a point, and the third part of the chapter touches briefly on Papua New Guinean concepts of property.

\section{Intellectual property rights: global resources and protection for people}

Intellectual property rights cannot be ignored as a tool in international law, but why are intellectual property rights a global issue? What public expectations do they raise? The hope for new raw materials, the thought of new ways to gain from old ones, and perhaps even the idea that if one lost out in earlier distributions of resources, here one can be in at the beginning, and the recognition of diverse actors in the field all play their part. $^{1}$

\section{New things: new products}

Competition is one impetus to create new economic products. Resource hunting by companies for usable products and new uses leads to the discovery of new materials (things) to which economic value can be attached; biotechnology companies may rate success in terms of numbers of patents. This contributes to the pace of technological innovations in the industrialised world, and the commercial expectation that anything exploitable should be exploited alerts people to hitherto unseen possibilities.

New inventions lead to value being put on both the inventive capacity itself and the knowledge behind it. Intellectual property rights encourage inventors to spread their knowledge (rather than keeping it 
secret) once they have secured recognition. Intellectual property rights can thus be applied to things still in the making - it is possible to patent a manufacturing process as well as a product, and that may come to cover uses as yet unanticipated. In pointing to future economic potential, it appeals to the imagination. In effect it invites people to ask how they can put their knowledge to future use. 'Prospecting' of all kinds is characterised by a high degree of awareness that change signals more change. Provision is made for the uncertainty of what will be an asset in the future. Many things hold potential. The question behind patenting-whose knowledge was put to use?-alerts people to putting value on what might be useful.

New ways of thinking about existing products emerge. Value put on knowledge as a resource and on the acknowledgment of creativity in authorship leads to reflection on knowledge already made useful, and thus already embedded in artifacts (design), persons (in the form of intention ${ }^{2}$ and transferable skills) and practices (medical remedies). Such knowledge (for example, ethnobotanical classifications) may be an aid to future discoveries or, in coming to be valued in its own right, evokes what is already in place. The general idea of cultural property as embedded knowledge is a prime example. The question behind copyright-who is the original author?-raises expectations about assigning property rights to all kinds of products attributable to past human creativity.

\section{New relations: new social actors}

The widespread consensus that economic growth is key to the survival of political institutions such as the state underwrites agreements endorsing national sovereignties. Nation states are not new, but the kinds of relations that state agencies have with aboriginal peoples ('first nations') as well as with transnational corporations are being constantly refashioned. Intellectual property rights flourish in a social context energised by the relationship of national innovation to globalisationwill national interests get increasingly competitive or dissolve in the face of multinational and other conglomerates? The phenomenon of interlinked economies shows persistent national differences as the driving force behind the globalisation of technology (Bartholomew 1997). ${ }^{3}$ The expectation that national interests are people's interests is written into many inter(trans)national agreements.

Agreement that the protection of property rights is an issue of worldwide concern is embedded in organisations (such as non govern- 
ment organisations) and social instruments beyond the state. The former disseminate information and thus act as knowledge brokers across national boundaries. The latter include ways of dealing with access to and protection of resources beyond an exclusively national perspective, including soft law regulations. ${ }^{4}$ They create expectations both of free movement (for example, knowledge of what other groups are doing) and of regulation (international agreements) beyond the state.

Acknowledgment that human rights make it necessary to single out categories such as indigenous peoples and women assists the formalisation of interest groups. ${ }^{5}$ This has created unprecedented possibilities for enfranchising local interests through a global identity (indigenous groups may or may not be coterminous with the nation).

Expectations of intellectual property rights are played out in advocacy and opposition. Both enthusiasm for and criticism of intellectual property rights touch equally on property thought of as a thing and property thought of as rights between persons with respect to a thing.

\section{Enthusiasm for intellectual property rights: advocacy}

Things. Intellectual property rights are seen as a legal instrument that will allow indigenous communities to assert claims on the international stage in a manner hardly yet possible. ${ }^{6}$ The very idea of intellectual property lends itself to all kinds of creativity. What helps technology also helps indigenous activists who have in the past struggled for a voice

Indigenous knowledge, historically scorned by the world of industrial societies, has now become intensely, commercially attractive... At bottom, intellectual property rights consist of efforts to assert access to, and control over, cultural knowledge and to things produced through its application. [Among those who] seek equity for the world's indigenous peoples the thought arises, why couldn't indigenous peoples own their cultural knowledge, and then, if they allow it to be used elsewhere, secure a just share of the money it generates (Greaves 1994: ix, 4).

Relations. Intellectual property rights are premised on a sense of equity, the two-way flow of knowledge and recompense. They do not just create a legal arena to protect rights, they give power to new social actors, that is, the legal 'person' identified as inventor or author in whom the property rights are invested. Such persons are legally individuals ('juridical persons'), a concept which can include corporate bodies such as government agencies or research institutes. Any social unitindividual, clan or village-could theoretically seek registration as a juridical person and thus as a potential right holder. 


\section{Criticism of intellectual property rights: opposition}

Things. Not everything can be considered as a thing to be owned, for in Euro-American thinking, ownership implies the right of alienation (disposing of the thing to another, for example, through sale or as a gift). The question of what can and cannot be alienated is often answered in terms of the kind of thing at issue. Thus many Euro-Americans regard nature as a common resource for humankind that should not be allocated to specific owners. The question then focuses on exactly what nature is.

When the European Parliament in July 1997 debated a directive for the legal protection of biotechnological inventions to give companies the right to patent organisms created through microbiological processes, one opponent referred to this as 'a charter to enslave nature'. Organisms are not appropriately owned in this thinking, nor is 'life'. This comes from a Euro-American preoccupation with things as objects of manipulation; any entity that is a person (subject) or of human material or simply animate may be protected from object-like status. It also comes from the idea of nature as a resource to be freely shared. To assert property rights is to diminish the commons (resources from which no one is by right excluded).

Social relations. The question of what can and cannot be alienated is answered in terms of people's relationships with one another.

Opponents of intellectual property rights may see them as asserting a form of private property that challenges the ethos of sharing that they would attribute to collective ownership typical of indigenous communities. Generations of people are responsible for building up cultural knowledge. Not to acknowledge this is to deny people's cultural and inalienable heritage.

Contemporary intellectual property law is constructed around the notion of the author as an individual, solitary and original creator... Those who do not fit this mode-custodians of tribal culture and medical knowledge, collectives practising traditional artistic and musical forms, or peasant cultivators of valuable seed varieties-are denied intellectual property protection. For members of indigenous peoples, knowledge and determination of the use of resources are collective and intergenerational (Bellagio and COICA statements, Posey 1996b:13).

Intellectual property rights seem a poor social register and may even set people against one another. If the identification of individual authors or inventors becomes problematic in light of traditional authorship and collective inventions, then the identification of individual property 
holders becomes problematic in the light of multiple claims. Even if a group can be identified, who belongs to the group? Who is the representative to speak on its behalf? What about power inequalities between different interests within the group?

\section{Points for debate}

Intellectual property rights are derived from Euro-American culture. Euro-American critics themselves emphasise this, and seize on individualism and private property as the principal problems. Some evoke an older European vocabulary through appeal to community and practices of sharing in the free transmission of knowledge. This vocabulary seems to mesh well with similar criticisms that come from communities proclaiming traditional rights or different kinds of relations with nature. One might conclude that these criticisms indicate how to put indigenous culture on the map. ${ }^{8}$ If Papua New Guinea is to identify itself with indigenous and traditional values, then it might already have the tools for a Papua New Guinea response. But perhaps the conclusion is premature, for it does not follow that current criticisms of intellectual property rights automatically indicate a Papua New Guinea way. Debate about these issues should question the assumptions behind the way intellectual property rights are opposed, as well as those by which it is supported.

Euro-American ambiguity towards property (see the Annex at the end of this chapter) fuels both enthusiasm and antagonism towards intellectual property rights. Attacks on individualistic notions of property echo the kinds of criticism Euro-Americans make of their own practices. For 300 years they have railed against the individualistic connotations of property, and drawn on their own ideas of its opposite (communal forms of ownership) in order to do so. In the case of intellectual property, nineteenth century protesters resisted the idea that knowledge can be treated as property. This was regarded in Europe as both a practical and moral matter. The flow of ideas could not be controlled, but equally importantly, ideas are in essence free goods and, therefore, common property' (Brush 1993:655). Common property is equated not with collective identity but with unrestricted access.

Much critique was directed towards property as private and exclusive ownership, though one should note that the concept of property as a bundle of rights always allowed the recognition of multiple rights. One alternative to intellectual property rights which has received support 
from several quarters-traditional resource rights-adopts the bundle of rights idea (Posey 1996b; Posey and Dutfield 1996). This argues that resources can be best protected through recognising the diverse, overlapping principles embodied in multiple instruments and agreements that reflect whole bundles of different rights (for example, the right to self-determination, cultural heritage rights and the right to privacy), of which intellectual property rights form only one.

In the late twentieth century, Euro-American culture fuels the way in which much of the international community approaches both the exploitation of resources and the remedies to this. It provides both the language for the notion of intellectual property and a language for resistance. Across the world bodies have debated the utility of intellectual property rights in terms of the kinds of communal rights that should be asserted against those of individual ownership and the extent to which commodification (making things marketable) undermines the free sharing of resources. Euro-American assumptions about authorship and individuality have been attacked, and one welcomes the new international consensus that points to other ways of defining rights, notably the idea of collective rights. But does the model of collective rights have to be that of communal rights, and does the counterpoint to commodity have to be the sharing of resources?

This is not just an academic matter; there is a real need for a contemporary view. First, the things over which companies and nations compete are constantly changing and thus so are the kinds of rights people seek. If genetic material turns into an informational resource which can be used over and again without diminution (like a performance), its new character creates new problems and possibilities for asserting property rights (Parry 1997)-how do you keep track of multiple transactions?

Second, social realities are changing all the time, and stereotypes get out of date. It would be a mistake to stereotype all commercial firms as monolithic capitalist enterprises like armies out to occupy new terrains. For many, a better analogy would be the flexible and adaptable guerrilla who would seize opportunities but not wait around for them; whose dependence on raw materials may be no more than an initial step in a long process; who would be able to transform products to the extent that the original creators are left far behind. An exaggeration perhaps, but international organisations in technology development (where intellectual property rights remain significant) operate at diverse levels, 
for example, integrating basic and applied research between firms and research institutions. Companies do not just act as competitive individuals. Knowledge transfer becomes a new item of transaction, and alliances are established and communication networks are created. ${ }^{9}$

In sum, it would be a pity if particular Euro-American views of community and sharing led to definitions of practices that do not in the long run help in dealing with outside interests. These views pose their own problems - what might sound well in international debate may create unanswerable internal questions (including those concerned with what a community is and who has the right to share). Finally, we need to look at Papua New Guinea as is, not as defined in advance by the international community. So is there a Papua New Guinea way?

\section{Transactions in Papua New Guinea}

\section{What is property in Papua New Guinea?}

This question could result in a huge matrix depicting all the kinds of things in which people have rights (for example, land, decorations, tankets ${ }^{10}$ and pigs), alongside the relations involved, both the nature of the right (ownership, possession, stewardship or usufruct) and the categories of social person who may be right holders (chief, clan, sister or individual). Within the matrix, one would find rights to intangibles as the product of intellectual or creative effort-magical spells, habits purchased from seniors, rights of entry into grade associations, malanggan designs (where it is not the figures but the images that circulate), as well as myth, songs sung on particular occasions and ritual styles (Harrison 1992). But there are many songs, styles, and indeed, whole areas of knowledge that one would not consider property in the same way. And there are many ways in which persons exercised rights in relation to one another that one would not necessarily wish to call property rights. What is the difference?

Some would say the question is pointless. In this view the very idea of property seems inappropriate to the Papua New Guinea situationeverything is implicated in everything else, and property simply distorts the holistic nature of indigenous realities. Although there is truth to this view, there would be some use in developing a counterpart to the international term 'property'. 
The Papua New Guinea situation throws into relief the limitation of focusing only on things (items in which people have rights) or on relations (how those rights are held between persons). This focus can of course be developed to allow for multiple rights; it can be stretched to accommodate so-called forms of communal property. But it forces attention onto the identity of the things (such as sacred sites and botanical knowledge) or the identity of the social persons claiming rights (the clan as a right holder or the individual who claims usufruct), and moreover onto identity already established (as when people say that long-standing community values are threatened by property claims). A third dimension also demands attention.

\section{Property through transactions?}

Perhaps one answer to the question of what constitutes property in Papua New Guinea is that there is property where there has been a transaction. Papua New Guinean practices introduce the idea that rights may be defined by the process of transaction itself. This perspective would bring Papua New Guinea closer to international understandings of contract. It would also deal with a crucial dimension of Papua New Guinea social reality. Many things (tangible and intangible) are regarded as derived from other persons-creativity or knowledge frequently passes from one person to another, so that a person has rights by virtue of his relations with other persons. This includes the life and/ or body that, in some societies, a mother's brother gives to his sister's children. This does not just mean that a person holds right of possession against other persons or by virtue of courts of law to uphold them. It means that the possession is itself created out of social relationships because the thing in which the rights are exercised embodies that relationship. Euro-Americans may think in similar terms but do not build the kind of social practices out of them that are found in Papua New Guinea. Two sets of practices are relevant here.

The first comes from the familiar case of multiple rights. A right may be invested in the individual but the individual is embedded in relationships. Land holding is a common example. For the case of intellectual products, consider a carved design owned by $\mathrm{X}$ by virtue of the fact that $\mathrm{X}$ belongs to clan $\mathrm{Y}$. The design is also owned by the clan, even though no other clan members may exercise that right on an individual basis till the right holder dies. Alternately the carving may 
have been derived from inspiration inculcated by a master (Kasaipwalova 1975). What typifies such rights is that they are exercised in specific contexts. Often the social relations (for example, clan membership or apprenticeship) are made evident at the same time as the right is. Preexisting identities are not sufficient. If people have the right to perform certain acts, such as mortuary service, this is held in relation to specific others (for example, the deceased's kin), and is realised only in their company on that specific occasion. The right of a mother to eat the bridewealth pig for a daughter may affect none of her claims over pigs until the occasion when that right is mobilised by the relationships brought into play at marriage. The thing produced or the performance enacted embodies relationships-the bridewealth pig is a vehicle for the relationships the mother has with both her daughter and with her in-laws; an artist and his ancestors together produce an image, and the (making of the) image itself incorporates that relationship. However, the extent to which such relationships entail overt 'transactions' varies.

The second, the extent to which rights are defined by having something to dispose, is less familiar outside Papua New Guinea. It may also be the case that within Papua New Guinea it is more salient in some regions than in others. In the Western Highlands the ability to pass something on may be circumscribed (for example, a man may gift a pig where a woman cannot) but nonetheless be a prerogative. The converse is acquisition, where the ability to acquire rests not in the nature of the thing but in the relationship between parties agreeing to the transactability of the item (like contracts). The grounds may be those of recompense (as in exchange or donation), kinship (as in inheritance), learning (as when a junior gains knowledge from a senior), intent (in preparing a garden) or inspiration (as when someone dreams a design). While these are based on prior relationships, the relationships have built into them an expectation of transaction or disposability. One might talk of the right to endow, as when one group of men endows another with a woman in marriage-for the right to endow (so to speak) usually carries the benefit of eliciting a counter-endowment (for example, sister exchange). Claims may or may not be exclusive; in some cases a crucial component of A's acquisition of things is the fact that he or she obtained them from B. There may be a coercive elementtransactions lead to transactions, solicitory gifts to return gifts; plants in the ground belong to the planter but are intended for another who has 
exclusive rights of consumption. The same things are disposable in some situations and not in others. The point is that things may embody relationships as the process of attachment and detachment. Sillitoe (1998) refers to the right of disposal-we might consider this a property relation.

\section{Some corollaries for intellectual property}

Papua New Guinean knowledge and creativity is both embedded and transactable. Perhaps we should be looking for conditions of transaction (not forgetting that exclusion or inclusion-property-may work here as anywhere else). The above leads to much misunderstood practices of reciprocity; reciprocity is entailed precisely because one party involves another. It is not itself inherently virtuous. But it means that there is no simple confrontation between communal versus individual rights-we are dealing with specific interests embedded in relations between persons.

That things reify relations is often misunderstood as mercenary interest. If there is value in transforming human relations into things which can be transacted, does this entail a right (just as the international community transforms relations into documents, often under scrupulously adjudicated circumstances)? This is not just sharing versus commodification. If technological process is criticised (as, for example, in the case of the commodified seed that does not reproduce (Shiva 1992)), what about reproduction through transactions as such? The right to reproduce may entail the right to bestow ('life' and 'body', in the form of things, on future generations).

The idea of relations transactable in things leads to a proliferation of compensation practices (Filer 1997). Opponents of intellectual property rights may claim that one cannot identify the individual author under indigenous regimes where innovations are cumulative, and then attack the whole idea of payment. But payment in Papua New Guinea precisely means making intangibles tangible. The question is what you can and cannot make material. Payment for intellectual property is criticised for imposing the Euro-American split of mind from body, as in the transformation of community economies to market ones. But where there is no division between persons and things, then the practice of eliciting specific knowledge or assets through the payment of things may be a sui generis mode of dealing with relations between persons. Of course it may lend itself to market forms, and to successful or unscrupulous behaviour. Nonetheless there are interesting hints for 
looking at international conventions of contract and further research is needed.

These observations about transactions in Papua New Guinea are somewhat tentative and speculative. They may or may not be useful in the present context. It remains the case, nonetheless, that whatever place intellectual property rights hold in people's imagination and expectations, transactions will play a major part.

If getting instruments in place to divert the Convention on Biological Diversity protocols into local channels is difficult, the potential of compensation as an enabler of a modernised indigenous order promises to burst the banks. Its power lies in the very way in which equivalences are set up between human values (persons and relations) and things. There will be no problem about sweeping into the arena of compensation practices all manner of inventions and innovations. This is not because there is no clear distinction between work and resources or between control over knowledge and rights established through the exertions of those to whom one is related. Rather, the issue is the power of transactions to define interests in resources-for those transactions in turn expand people's capacity for social relationships, whether between the transacting parties or in relation to others, offering both old and new bases for power relations.

There is opportunity for a fresh look at intellectual property rights as at once an enablement and a problem. Many critiques about individualism and commercialism reinvent old sources of EuroAmerican criticism. They are as valuable, and as limited, as the notions of property that they seek to modify. The Papua New Guinea way would be to add richness, complexity and a different kind of realism to both sides of the debate. 


\section{Annex}

\section{Diverse perspectives on Euro-American ideas about property}

Property has carried radically different connotations at different moments in European history (Hann 1997). For example, Roman law, foundational in many continental European countries, identified ownership with the thing owned. Property was capable of infinite division, as in peasant Europe, where landholdings would be divided into smaller and smaller parcels among heirs. Things were thus divided between persons by being split into shares. Title inhered in the thing owned (for example, an estate) to which persons became attached, and only certain things were regarded as property (movable or immovable goods). Communal property comes from the idea of persons held together by common bonds in a piece of property which they share.

Compare common law, as practised in England, following feudal holdings, which rendered the thing indivisible so what was divided was rights among people. Thus things are not divided: rights in them are, and any one thing might have several owners. People could thus buy and sell rights in things without altering the thing itself, a system that allowed intangible entities such as copyright and patents to be regarded as forms of property. Since the right inhered in the individual person, this was also the precursor of private property. Private property entails the right to exclude others, and common property, the individual's right not to be excluded.

Nineteenth century objections to private property (capital) derived from longstanding debates over labour; if people have a right to enjoy the products of their labour, when labour can be bought and sold, what rights has the new 'owner' gained? One response: the wage labourer sells his time, but his person remains free. Counter-response: labour is already defined as on the market; the labourer is not free to dispose of his or her labour otherwise. Models of communal enterprises to which people instead contributed their collective efforts was one solution to this impasse.

Property is tied up with specific political as well as economic systems, for example, protection of individual rights within a state system. What protects one person (claims to the usable products of their activities) may exploit others (disregard for other kinds of claims). It is the doubleedged character of property (protection for this person, exclusion of 
that) that makes it at once a highly moral and highly dubious construct. Throughout modern European history property has been a source of indigenous (European) contest.

Many twentieth century Euro-Americans are concerned about commodification. Part of the above politics has been the human rights insistence that persons should not be treated like property. Property is bound up with social identity, whether corporate (as in attachment to estates) or individual (authorship). It is when it comes to buying and selling that some things are properly regarded as alienable and some as not. A person may have title but still be restricted as to how to dispose of property (including, for example, the restrictions posed by inheritance laws), but the issue of monetary gain adds a further dimension to what are perceived as sometimes acute moral dilemmas. The European Community biotechnology directive led to an outcry at the point when it seemed to be sanctioning the commodification of human material. Embryo research and the 'ownership' of organs and body parts interfere with European notions of 'life'. It is interesting that one solution to thinking about rights in embryos outside the body (created through reproductive technology) has been that of dispositional control-rights in disposal (Robertson 1994).

\section{Notes}

1 Perhaps much activity from former colonial states gains impetus from what are perceived to be past inequities to be rectified rather than from a realistic estimation of current realities. Compare the 'futuristic' connotations of bioprospecting with the whole issue over the protection of food varieties, especially in grain-growing countries (Shiva 1992).

2 American litigation over parental rights in the context of new reproductive technology has, by analogy with intellectual property rights, included attempts to establish a claim through the 'intention' to reproduce.

3 Diversity of national policies and regulations flourishes. Attempts by the European Community in 1997 to harmonise laws of member states relating to biotechnology is a case in point. The United States is particularly typified by increasing protectionist legislation for intellectual assets.

4 Soft law refers to declarations of principles, codes of practice, 
recommendations, guidelines, standards and resolutions. Although such documents are not legally binding, there is a strong expectation that they will be respected by the international community. The evolution of customary international law is accelerated by including customary principles in soft law agreements and non-governmental declarations; these become hardened through worldwide acceptance (Posey and Dutfield 1996:120).

5 Posey and Dutfield (1996) include texts of the Declaration of Principles of the World Council of Indigenous Peoples (1984); UN Draft Declaration on the Rights of Indigenous Peoples (1993); KariOca Declaration and the Indigenous Peoples' Earth Charter (1992); Charter of the Indigenous-Tribal Peoples of the Tropical Forests (1992); the Mataatua Declaration on Cultural and Intellectual Properly Rights of Indigenous Peoples (1993); Recommendations from the Voices of Earth Congress (1993); UNDP Consultation on the Protection and Conservation of Indigenous Knowledge (1995); and UNDP Consultation on Indigenous Peoples' Knowledge and Intellectual Property Rights (1995).

6 But the number of cases where this has happened successfully is small. For example, it would be possible for tribal rights to a folk variety of plant to be asserted through the US Plant Variety Protection Act, although no 'tribe' has to date deployed this mechanism (cited in Brush and Stabinksky 1996).

7 Intellectual property rights began with the early modern state in Europe breaking the monopolies of guilds in giving individual authors rights to the products of their exertions.

8 For example, the Charter of the Indigenous-Tribal Peoples of the Tropical Forests (Article 40) specifies that: 'Programmes related to biodiversity must respect the collective rights of our peoples to cultural and intellectual property'.

9 Small start-up biotechnology firms collaborate with larger firms - the former carry the risk of innovation and offer specialist expertise, while gaining from the latter's access to marketing channels.

10 'Tanket' is a Tok Pisin word referring to a shrub (Taetsia fructicosa) and the leaves of that shrub. Tanket are symbolically important in many parts of Papua New Guinea. 